\title{
Inflammatory bowel diseases: time of diagnosis, environmental factors, clinical course, and management - a follow-up study in a private inflammatory bowel disease center (2003-2017)
}

This article was published in the following Dove Medical Press journal:

Journal of Inflammation Research

\section{DB Cury' \\ R Oliveira ${ }^{2}$ \\ MS Cury ${ }^{3}$}

'Inflammatory Bowel Disease Center, Scope Clinic, Campo Grande/MS, Brazil; ${ }^{2}$ Biostatistics, UNESP, Botucatu, São Paulo, SP, Brazil; ${ }^{3}$ Advanced Endoscopy Center, Scope Clinic, Campo Grande/MS, Brazil

Video abstract

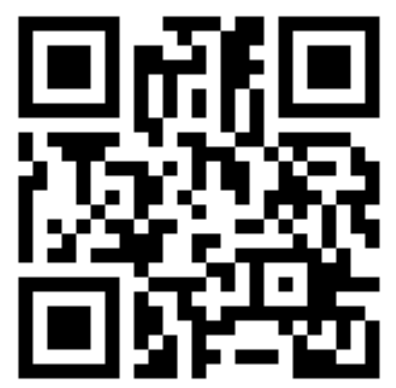

Point your SmartPhone at the code above. If you have a QR code reader the video abstract will appear. Or use: http://youtu.be/9lfDIEkvFMA
Correspondence: DB Cury Inflammatory Bowel Disease Center, Scope Clinic, Maracaju Street II48, Campo Grande/MS, Brazil

Tel +556733256040

Email didia_cury@uol.com.br
Background: The governmental program of Brazilian Unified National Health System has already published studies on the incidence of inflammatory bowel diseases (IBD), but up until now, there have been no epidemiological studies in private centers in Brazil. However, these diseases tend to affect people from a higher socioeconomic class, mainly in the capital of MS state that has the third highest GDP in Brazil.

Objectives: The aim was to analyze an observational, descriptive study of an IBD database in a private center including: the side, behavior of the disease and medical management, the association of extra-intestinal manifestations, and the main clinical symptoms which led to the investigation and diagnosis of IBD.

Patients and methods: A cohort study was developed in which data of all patients with IBD were analyzed with SPSS software in a constructed electronic database.

Results: Of 329 patients, 212 (64.4\%) had Crohn's disease (CD) and 117 (35.6\%) had ulcerative colitis (UC). Average age at diagnosis of CD was $36.19( \pm 14.33)$ and of UC was $41.61( \pm 15.37)$. An amount of $50.05 \%$ of the patients with $\mathrm{CD}$ and $72.7 \%(P<0.001)$ with UC were female. We have observed that concerning the first symptoms, diahrrea and blood feces corresponded to $70 \%$ in UC while in CD 50\% of the patients presented diahrrea with blood feces, loss of weight corresponded to $50 \%$ and only diahrrea $25 \%$. $(P<0.001)$. Anti-TNFs corresponded to $56.2 \%$ being more frequent in CD $0.001 \%$. CD patients used biologic therapy and antibiotics more frequently than those with UC. In conclusion, IBD is also frequent in private health care centers in Brazil; women are most affected. Symptoms such as diarrhea and bleeding, as well as diarrhea and weight loss, must be taken as warning signs to investigate for inflammatory disease. The use of biologic therapies is frequent in referral centers when patients have severe disease. Keywords: Crohn's disease, ulcerative Colitis, alert symptoms, behavior, anti-TNF, extraintestinal manifestations

\section{Introduction}

Inflammatory bowel diseases (IBD), including Crohn's disease (CD) and ulcerative colitis (UC), are chronic, recurrent diseases that affect mainly young people. ${ }^{1-3}$ Although these diseases have undetermined etiology, research advances have outlined some of the pathways by which they occur: 1) genetic predisposition associated with the environment induces a disruption of the intestinal microbial flora, 2) the epithelial cells and the immune system of the intestine itself determine the risk of developing the disease. ${ }^{4-6}$

Risk factors are related to damage to the intestinal mucosa barrier that induces increased permeability, causing a greater antibody antigen reaction and generating 
an exacerbated inflammatory response. ${ }^{7}$ Additionally, the increase in thrombotic phenomena in CD patients using oral contraceptives supports the hypothesis of participation in these vascular events. ${ }^{8,9}$ Surgical procedures such as appendectomy could induce an imbalance of the immune system, generating an inflammatory response that is exacerbated in patients with $\mathrm{CD} .{ }^{10}$ Another contributing factor is related to the residence of susceptible people, whereby residents of urban areas would be at greater risk due to pollution and excessive hygiene. Interestingly, local factors even seem to contribute to the development of IBD, which has been observed mainly in studies with immigrants who transition from low-incidence countries to high-incidence ones before adolescence, corroborating an increase in the number of people affected from high-incidence countries. ${ }^{11,12}$

In certain regions in Brazil, IBD has been a major reason for missing work and school ${ }^{13-16}$ and it affects mainly higher social classes. CD appears in people between 15 and 25 years of age, with the highest peak at 25 years of age, although other authors have stated that the highest incidence is between 30 and 40 years, while the disease is less frequent in people between the age of 60 and 70 years. Complementarily data have shown a higher prevalence among youngsters in recent years. ${ }^{17-25}$ Unfortunately, in Brazil, epidemiological data are scarce and generally refer to the public health system, based on hospitalization records or records of patients who purchase high-cost medications through the government. ${ }^{26-31}$ Although the main symptoms of the diseases are well-known in the literature, in Brazil up until now, there have been no studies on the main clinical signs and symptoms that could lead to investigation and diagnosis from the time of the onset of the symptoms to a defined diagnosis; in what way these diseases are present; which is the most frequent behavior; the associations of risk factors; what medical approaches have been attempted, and the incidence of complications over time.

\section{Objectives}

1. Establish the number of cases of IBD in an IBD private referral center in the Middle-West of Brazil.

2. Analyze the location and behavior of the disease and medical management.

3. Identify the association of extra-intestinal manifestations.

4. Recognize the main clinical symptoms which led to the investigation and diagnosis of the inflammatory disease.

\section{Methods}

This study was conducted during the period from 2003-2017 and was developed in a private referral center located in the
Central West region of Brazil after approval of the ethics committee.

It was performed by way of analysis of electronic records with different variables formed by a standard questionnaire applied at the first consultation of the patients with inflammatory disease, considering risk factors, beginning with the first signs and symptoms and including the total time from onset of symptoms to diagnosis. The Montreal classification was used in both diseases, and drug approaches were recorded over time, along with the evolution and complications of the disease and any annual revisions (2004 to June 2017).

Diagnostic criteria: all patients underwent colonoscopy with biopsy. In cases of negative colonoscopy and suggestive symptomatology, the patients underwent double balloon enteroscopy or endoscopy. In cases of previous history of tuberculosis bacillus, testing was performed on tissue, and the tuberculin test was administered. In previous diagnostic situations, both the examinations and the slides were reviewed and updated, if necessary, for both diseases. In addition, inflammatory tests were performed, such as C-reactive protein and erythrocyte sedimentation rate, fecal culture for research and proto-parasitological analysis and serology for HIV.

Treatment criteria followed those indicated by the global literature, taking into account the location of the disease and its extent and behavior. ${ }^{32-34}$

Follow-up criteria: patients with active disease were followed weekly until the improvement of the clinical picture or stabilization of the serum levels of C-reactive protein, hemogram, and erythrocyte sedimentation rate (ESR). Following symptom stabilization, patients were seen every 6 months, and follow-up enrollment data were updated and revised each year.

All univariate and bivariate statistical analyses were performed on the sample. The proportions observed in the categories of these variables were tested using the chi-squared test $\left(\chi^{2}\right)$, and differences were considered statistically significant when the risk of alpha error was lower than $0.05(P<0.05)$.

From the descriptive statistics, inferential tests were performed in tables, facilitating the interpretation of the association between the variables studied in the database. In addition, 95\% CIs were calculated for the risk factors of the contingency tables. Statistical analyses were performed using the statistical software Minitab ${ }^{\circledR} 16$ (Minitab Inc, State College, PA, USA) and SAS (SAS Institute Inc., Cary, NC, USA).

\section{Ethical approval}

This study was approved by the Research Ethical Committee of the Universidade Estadual Paulista "Júlio de Mesquita Filho" (protocol number CAAE: 53006516.0.0000.5411). 
The Ethics Committee has granted exemption from obtaining informed consent of the participants as this is an analysis of a retrospective databank of de-identified data. In addition to this, the study involved patients who were over 18 years old. The patients who were under-aged were considered according to the age of diagnosis. At Clinica Scope only patients over 18 years old are accepted; the age factor was only used as an indication of when the disease started.

\section{Results}

Three hundred and twenty-nine patients were diagnosed with IBD from July 2004 to December 2017; $n=329: 212$ had CD (64.4\%) and 117 had UC (35.6\%).

\section{Age}

The mean overall age was 38.12 years old $(\mathrm{SD} \pm 14.91) ; 36.19$ years old for $\mathrm{CD}$ patients $(\mathrm{SD} \pm 14.33)$ and 41.61 years old $(\mathrm{SD} \pm 15.37)$ for $\mathrm{UC}$ patients $(P=0.002)$.

\section{Gender}

There was a predominance of the female gender, corresponding to $72 \%$ of the overall study population (female:male ratio $=P<0.001)$ distributed between the diseases as follows: $50.5 \%$ in $\mathrm{CD}$ and $72.7 \%$ in UC $(P<0.001)$. The distribution of age according to the Montreal Classification was: A2 (55.6\%) was higher than A3 (42\%) and A1 (2.4\%) (Table 1).

\section{Educational level}

Regarding the educational level, $4.0 \%$ had finished elementary school, $47.6 \%$ high school, and $48.5 \%$ graduated (Table 1).

\section{Disease phenotype of IBD patients}

According to the Montreal classification applied to both diseases, we noticed the following distributions regarding the behavior and side of the disease: CD and UC (Table 2): there was no statistical significance.

Table I Demographic characteristics of population (IBD patients) in a private health care center West of Brazil

\begin{tabular}{|c|c|c|c|c|}
\hline Variables & $n=329$ & $C D(n=2 \mid 2)$ & $U C(n=I 17)$ & $P$ \\
\hline Female gender & $72(72.0 \%)$ & 107 (50.5\%) & $85(72.7 \%)$ & $<0.001$ \\
\hline Age, years (mean $\pm S D)$ & $38.12 \pm|4.9|$ & $36.19 \pm 14.33$ & $4 I .6 I \pm 15.37$ & 0.002 \\
\hline Age (Montreal), n (\%) & & & & 0.020 \\
\hline $\mathrm{Al}$ & $8(2.4 \%)$ & $6(2.8 \%)$ & $2(1.7 \%)$ & \\
\hline $\mathrm{A} 2$ & 183 (55.6\%) & 129 (60.9\%) & $54(46.2 \%)$ & \\
\hline $\mathrm{A} 3$ & $138(42.0 \%)$ & 77 (36.3\%) & $61(52.1 \%)$ & \\
\hline Education, n (\%) & & & & 0.340 \\
\hline Elementary school & $13(4.0 \%)$ & $9(4.3 \%)$ & $4(3.4 \%)$ & \\
\hline High school & 156 (47.6\%) & $94(44.6 \%)$ & $62(53.0 \%)$ & \\
\hline Graduate & 159 (48.5\%) & 108 (5I.1\%) & $5 \mathrm{I}(43.6 \%)$ & \\
\hline Ancestral origin, $\mathrm{n}(\%)$ & & & & 0.221 \\
\hline German & $21(6.4 \%)$ & $15(7.1 \%)$ & $6(5.1 \%)$ & \\
\hline Italian & $81(24.6 \%)$ & $49(23.1 \%)$ & $32(27.4 \%)$ & \\
\hline Japanese & $7(2.1 \%)$ & 7 (3.3\%) & $0(0.0 \%)$ & \\
\hline Other & $82(24.9 \%)$ & $5 \mathrm{I}(24.1 \%)$ & $3 \mathrm{I}(26.5 \%)$ & \\
\hline Portuguese & II (34.0\%) & 70 (33.0\%) & $42(35.9 \%)$ & \\
\hline Spanish & $26(79 \%)$ & $20(9.4 \%)$ & $6(5.1 \%)$ & \\
\hline Urban resident & $321(97.6 \%)$ & 207 (97.6\%) & 114 (97.4\%) & 1.000 \\
\hline Employed, n (\%) & & & & 0.155 \\
\hline No & $22(6.7 \%)$ & $15(7.1 \%)$ & $7(6.0 \%)$ & \\
\hline Retired & $34(10.4 \%)$ & $16(7.6 \%)$ & $18(15.4 \%)$ & \\
\hline Student & $5(1.5 \%)$ & $3(1.4 \%)$ & $2(1.7 \%)$ & \\
\hline Yes & 267 (8I.4\%) & 177 (83.9\%) & $90(76.9 \%)$ & \\
\hline Religion, n (\%) & & & & 0.073 \\
\hline Agnostic & $2(0.6 \%)$ & \begin{tabular}{|l}
$\mathrm{I}(0.5 \%)$ \\
\end{tabular} & $\mathrm{I}(0.9 \%)$ & \\
\hline Catholic & 238 (72.3\%) & 150 (70.8\%) & $88(75.1 \%)$ & \\
\hline Spiritualist & $\mathrm{I}(0.3 \%)$ & $0(0.0 \%)$ & $\mathrm{I}(0.9 \%)$ & \\
\hline Spiritist (religion) & $4(1.2 \%)$ & $4(1.9 \%)$ & $0(0.0 \%)$ & \\
\hline Protestant/Evangelical & \begin{tabular}{|l|}
$32(9.7 \%)$ \\
\end{tabular} & $26(12.3 \%)$ & $6(5.1 \%)$ & \\
\hline Not stated & $52(15.8 \%)$ & $31(14.6 \%)$ & $2 \mid(\mid 8.0 \%)$ & \\
\hline
\end{tabular}

Abbreviations: IBD, inflammatory bowel diseases; CD, Crohn's disease; UC, ulcerative colitis. 


\section{Distribution of new cases over time}

We noticed an increasing number of cases over time, with a peak in 2007 peak $(P=0.046)$ (Figure 1).

\section{Statistic analysis}

Initially all variables were analyzed descriptively. For the quantitative variables, this analysis was done by observing the minimum and maximum values, and the calculation of means and SDs. Absolute and relative frequencies were calculated for the qualitative variables.

For the comparison of means of two groups, Student's $t$-test was used. To test homogeneity between proportions, the chi-squared test ${ }^{(1)}$ or the Fisher's exact test ${ }^{(1)}$ was used. The software used for the calculations was SPSS 17.0 for windows. The level of significance used for the tests was $5 \%$.

Table 2 Clinical aspects of inflammatory bowel disease of UC patients

\begin{tabular}{|c|c|c|c|c|c|c|}
\hline \multirow[t]{2}{*}{ Group } & & & \multicolumn{3}{|c|}{ Age (Montreal classification) } & \multirow[t]{2}{*}{ P* } \\
\hline & & & Al & A2 & A3 & \\
\hline \multirow[t]{10}{*}{$C D$} & Behavior, n (\%) & & & & & 0.116 \\
\hline & $\mathrm{BI}$ & $146(68.9)$ & $3(50.0)$ & $82(63.8)$ & $61(79.2)$ & \\
\hline & B2 & $36(17.0)$ & $2(33.3)$ & $24(18.6)$ & $10(13.0)$ & \\
\hline & B3 & $18(7.6)$ & $0(0.0)$ & $12(9.3)$ & $4(5.2)$ & \\
\hline & $P$ & $14(6.6)$ & $\mathrm{I}(\mathrm{I} .7)$ & II (8.5) & $2(2.6)$ & \\
\hline & Side, n (\%) & & & & & 0.828 \\
\hline & $\mathrm{LI}$ & $79(37.4)$ & $3(50.0)$ & $50(39.1)$ & $26(33.8)$ & \\
\hline & $\mathrm{L} 2$ & $42(19.9)$ & I (I6.7) & $25(19.5)$ & $16(20.8)$ & \\
\hline & L3 & $89(42.2)$ & $2(33.3)$ & $53(41.4)$ & $34(44.2)$ & \\
\hline & $\mathrm{L} 4$ & $I(0.5)$ & $0(0.0)$ & $0(0.0)$ & $\mathrm{I}(\mathrm{I} .3)$ & \\
\hline \multirow[t]{9}{*}{ UC } & Disease severity, $\mathrm{n}(\%)$ & & & & & 0.591 \\
\hline & So & $5(4.4)$ & $0(0.0)$ & $3(5.6)$ & $2(3.4)$ & \\
\hline & $\mathrm{SI}$ & $47(40.9)$ & $0(0.0)$ & $23(42.6)$ & $24(40.7)$ & \\
\hline & S2 & $45(39.1)$ & $\mathrm{I}(50.0)$ & $22(40.7)$ & $22(37.3)$ & \\
\hline & S3 & $18(15.7)$ & $\mathrm{I}(50.0)$ & $6(11.1)$ & II (18.6) & \\
\hline & Disease extent, n (\%) & & & & & 0.707 \\
\hline & EI & $52(45.2)$ & $0(0.0)$ & $26(48.2)$ & $26(44.1)$ & \\
\hline & E2 & $49(42.6)$ & $2(100.0)$ & $22(40.7)$ & $25(42.4)$ & \\
\hline & E3 & $14(12.2)$ & $0(0.0)$ & $6(11.1)$ & $8(13.6)$ & \\
\hline
\end{tabular}

Note: *Descriptive level of probability of Fisher's exact test.

Abbreviations: UC, ulcerative colitis; CD, Crohn's disease.
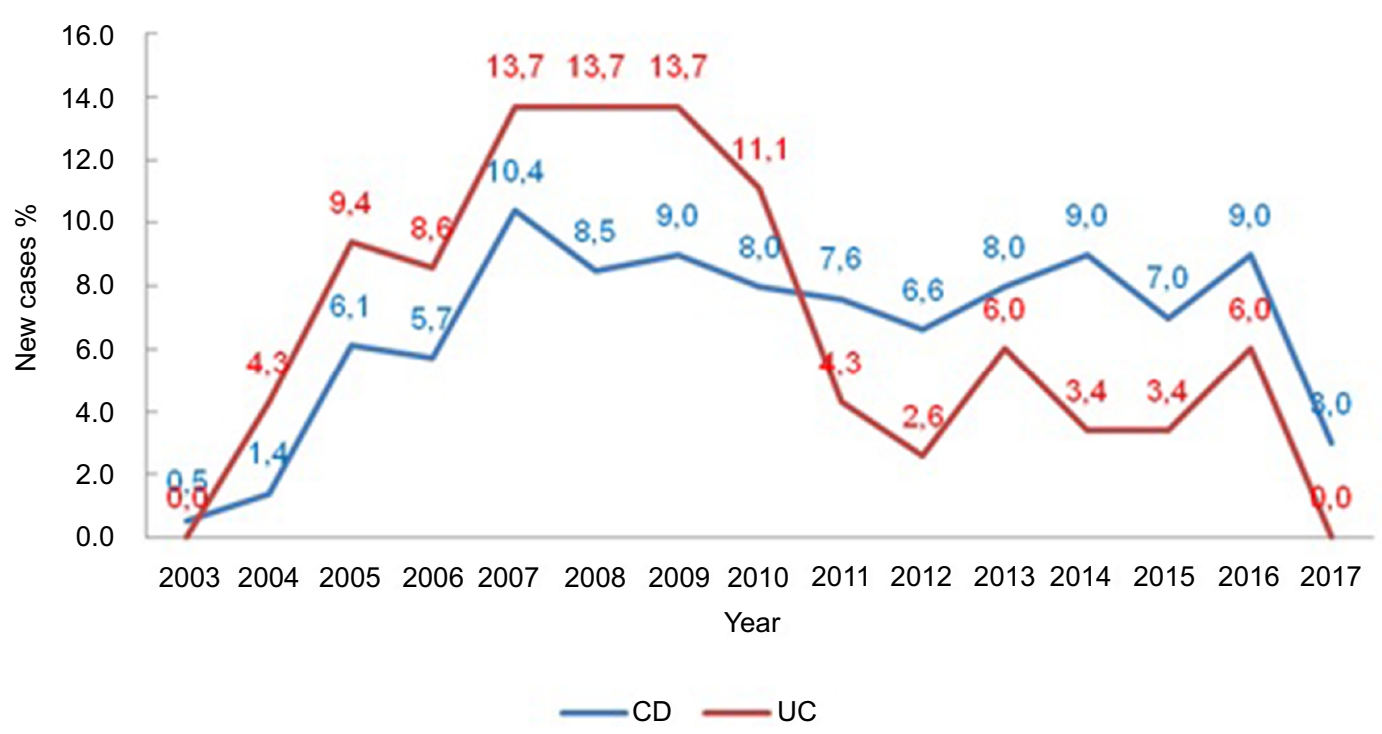

Figure I Percentage of new cases per year, according to the study group.

Abbreviations: CD, Crohn's disease; UC, ulcerative colitis. 


\section{Environmental factors}

In the analysis of environmental factors, $97 \%$ of the patients lived in an urban area, $15.5 \%$ of them smoked, $30.1 \%$ used anti-inflammatories, $10 \%$ used oral contraceptives, $17.9 \%$ had a family history of inflammatory disease, $9.7 \%$ had had appendectomies, and $6.7 \%$ had had tonsillectomies (Table 3). Comparing the groups ( $\mathrm{CD}$ and $\mathrm{UC}$ ) in relation to the risk factors, no statistical difference was noticeable.

\section{Main symptoms}

Among the main symptoms that led to the investigation and diagnosis were diarrhea and bleeding (31.3\%), weight loss $(19.8 \%)$, diarrhea (18.5\%), diarrhea and weight loss (12.2\%), diarrhea and abdominal pain (11.3\%), abdominal pain $(6.4 \%)$, and bleeding $(0.6 \%)$. The comparison between the groups is presented in Table 4 . In $\sim 70 \%$ of UC cases the first symptom was diarrhea/bleeding. In CD, $25 \%$ presented with weight loss and $25 \%$ with diarrhea. After analyzing the study groups in relation to the first symptoms, a statistical difference was noticed between the symptoms and the groups $(P<0.001)$ (Table 4)

Table 3 Environmental risk factors for inflammatory bowel disease

\begin{tabular}{|c|c|c|c|c|}
\hline \multirow[t]{2}{*}{ Variables } & \multicolumn{3}{|l|}{ Group } & \multirow[t]{2}{*}{$P$} \\
\hline & $n=329$ & $\begin{array}{l}C D \\
(n=2 \mid 2)\end{array}$ & $\begin{array}{l}\text { UC } \\
(n=\mid 17)\end{array}$ & \\
\hline Oral contraceptive pill & $33(10.0)$ & $19(9.0)$ & $14(1.0)$ & 0.385 \\
\hline Anti-inflammatory & $99(30.1)$ & $65(30.7)$ & $34(29.1)$ & 0.762 \\
\hline Smoking & $5 I(15.5)$ & $37(175)$ & $14(12.0)$ & 0.188 \\
\hline Family influence & 59 (I7.9) & $38(17.9)$ & $21(18.0)$ & 0.996 \\
\hline Appendectomy & $32(9.7)$ & $21(9.9)$ & II (9.4) & 0.883 \\
\hline Tonsillectomy & $22(6.7)$ & $13(6.1)$ & $9(7.7)$ & 0.588 \\
\hline
\end{tabular}

Notes: Data are presented as $n(\%)$

Abbreviations: $\mathrm{CD}$, Crohn's disease; UC, ulcerative colitis.

Table 4 First symptoms in patients with inflammatory bowel diseases

\begin{tabular}{|c|c|c|c|}
\hline First symptoms & $n=329$ & $\begin{array}{l}\text { CD } \\
(n=2 \mid 2)\end{array}$ & $\begin{array}{l}\text { UC } \\
(n=I \mid 7)\end{array}$ \\
\hline Diarrhea/bleeding & $103(31.3)$ & $21(9.9)$ & $82(70.1)$ \\
\hline Weight loss & $65(19.8)$ & $54(25.5)$ & II (9.4) \\
\hline Diarrhea & $61(18.5)$ & $54(25.5)$ & $7(6.0)$ \\
\hline Diarrhea/weight loss & $40(12.2)$ & $34(16.0)$ & $6(5.1)$ \\
\hline Diarrhea/abdominal pain & $37(11.3)$ & $28(13.2)$ & $9(7.7)$ \\
\hline Abdominal pain & $21(6.4)$ & $21(9.9)$ & $0(0.0)$ \\
\hline Bleeding & $2(0.6)$ & $0(0.0)$ & $2(1.7)$ \\
\hline
\end{tabular}

Notes: Data are presented as $n$ (\%).

Abbreviations: $\mathrm{CD}$, Crohn's disease; UC, ulcerative colitis.

\section{Time of diagnosis}

The time from symptom onset until definitive diagnosis was 62.4-76.3 months and was greater in UC patients (Figure 2).

\section{Medication}

Among the drug approaches, the distribution during this time was $56.2 \%$ anti-TNFs, $44.4 \%$ mesalazine, $31.9 \%$ azathioprine, $13.7 \%$ Cipro and Flagyl, $8.5 \%$ probiotics, $3 \%$ methotrexate, $2.1 \%$ vedolizumab, $1.8 \%$ hyperbaric oxygen therapy, $0.6 \%$ cyclosporine, $0.3 \%$ tacrolimus, and $0.3 \%$ stem cells (Table 5).

Extra-intestinal manifestations were present in $38.9 \%$ of cases, the most frequent being dry eye (17.6\%), kidney stones $(17.3 \%)$, and osteopenia (15.2\%) (Table 6).

\section{Patients' follow-up}

Surgical approaches were much more frequent in $\mathrm{CD}$ patients. Of these patients, $15.9 \%$ had abscess drainage, $3.95 \%$ had endoscopic balloon dilation stenosis, $5.47 \%$ underwent resection of the small intestine, and $1.52 \%$ underwent surgical resection of stenotic lesions $(0.91 \%)$. CD patients underwent a greater number of surgical approaches than those with UC $(P<0.001)$. During the study period, there were no cases of neoplasia, and one CD patient died due to complications inherent to the disease (intestinal obstruction).

\section{Discussion}

Abundant evidence has revealed the increasing incidence of intestinal inflammatory diseases in the world. The different forms of presentations of the disease could be related to the influence of the environment in which it exists..$^{35-39}$ Therefore, it is considered of paramount importance to make an early diagnosis in order to quickly start treatment for these conditions. ${ }^{40-43}$

The research presented here followed 329 patients for 14 years; of these, 212 had CD, and 117 had UC (Table 1). According to our data there was a greater number of cases of CD when compared to UC. It is likely that as CD is more severe than UC, patients suffering from this disease seek referral to IBD centers, although the literature has pointed out an increase in this disease all over the world.

National data show that in 2016, the per capita GDP of Brazil was USD8,649.95; the city of Campo Grande, the capital of Mato Grosso do Sul state, represented the third largest income, which is where this study was developed, in a private health care center that is a referral center for inflammatory intestinal diseases. Concerning the prevalence 


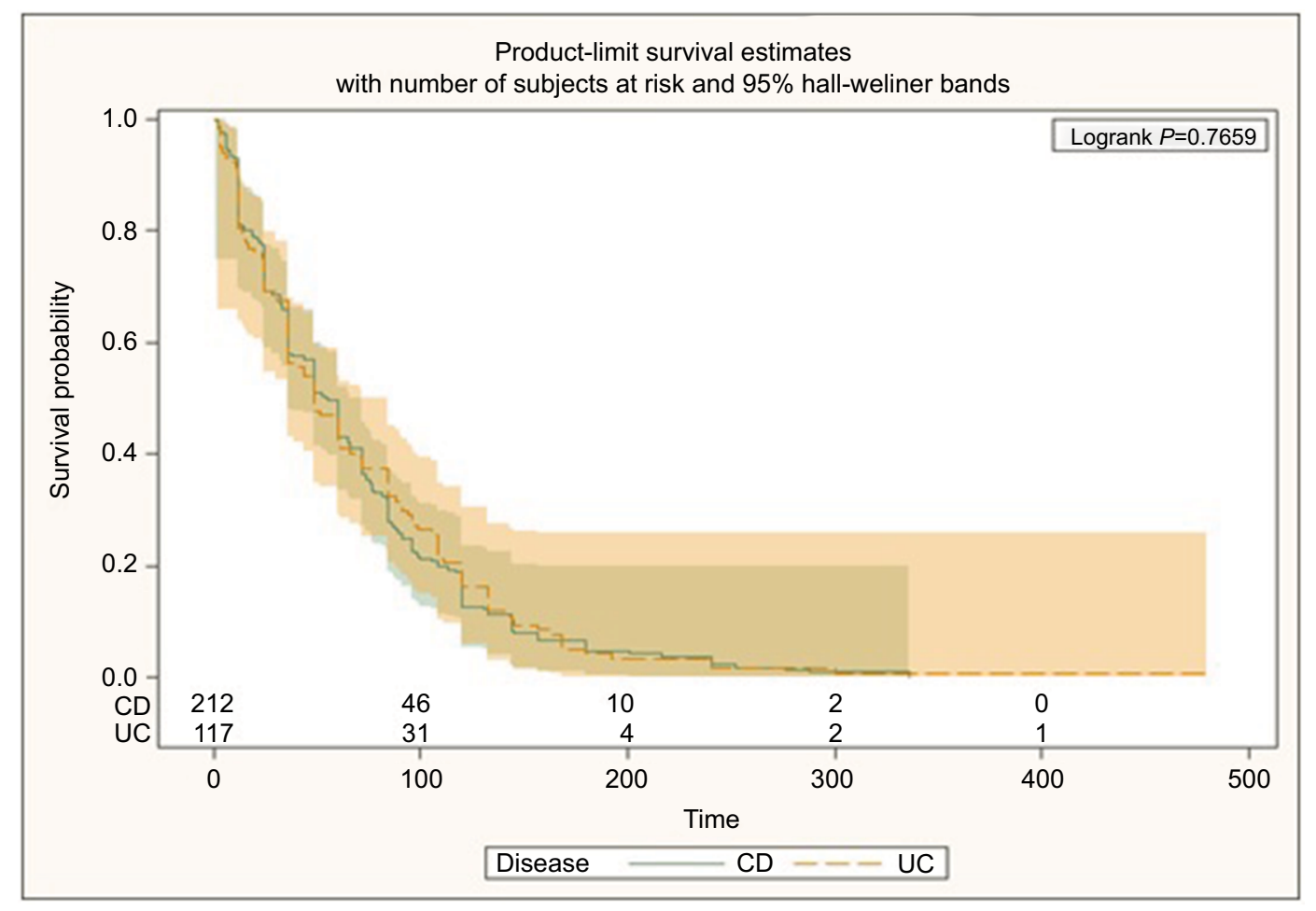

Figure 2 Time taken from the beginning of the symptoms up to the diagnosis of inflammatory bowel disease.

Abbreviations: $C D$, Crohn's disease; UC, ulcerative colitis.

Table 5 Medication and medical approaches in inflammatory bowel disease patients

\begin{tabular}{|c|c|c|c|c|}
\hline Medication & $(n=329)$ & $\begin{array}{l}\text { CD } \\
(n=2 \mid 2)\end{array}$ & $\begin{array}{l}\text { UC } \\
(n=|| 7)\end{array}$ & \\
\hline Anti-TNF & $185(56.2)$ & I33 (62.7) & $52(44.4)$ & $0.00 \mathrm{I}^{\mathrm{a}}$ \\
\hline $5 \mathrm{AZA}$ & $146(44.4)$ & $95(44.8)$ & $51(43.6)$ & $0.83 \mathrm{I}^{\mathrm{a}}$ \\
\hline Humira & $145(44.1)$ & $104(49.1)$ & $4 I(35.0)$ & $0.014^{a}$ \\
\hline AZA & $106(31.9)$ & $71(33.5)$ & $34(29.1)$ & $0.409^{a}$ \\
\hline IFX & $96(29.2)$ & $73(34.4)$ & $23(19.7)$ & $0.005^{\mathrm{a}}$ \\
\hline Cipro & 45 (I3.7) & $37(17.5)$ & $8(6.8)$ & $0.007^{\mathrm{a}}$ \\
\hline Flagyl & 45 (I3.7) & $37(17.5)$ & $8(6.8)$ & $0.007^{a}$ \\
\hline Probiotics & $28(8.5)$ & $23(10.9)$ & $5(4.3)$ & $0.04 I^{\mathrm{a}}$ \\
\hline MTX & $10(3.0)$ & $10(4.7)$ & $0(0.0)$ & $0.016^{b}$ \\
\hline Vedo & $7(2.1)$ & $7(3.3)$ & $0(0.0)$ & $0.054^{b}$ \\
\hline Hyperbaric $\mathrm{O}_{2}$ & $6(1.8)$ & $6(2.8)$ & $0(0.0)$ & $0.093^{b}$ \\
\hline Ciclo sp & $2(0.6)$ & $0(0.0)$ & $2(1.7)$ & $0.126^{\mathrm{b}}$ \\
\hline Tacrolimus & $\mathrm{I}(0.3)$ & $0(0.0)$ & $\mathrm{I}(0.9)$ & $0.356^{\mathrm{b}}$ \\
\hline Stem cell therapy & I (0.3) & I (0.5) & $0(0.0)$ & $1.000^{\mathrm{b}}$ \\
\hline
\end{tabular}

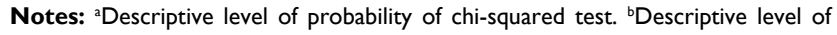
probability of Fisher's exact test. Data are presented as $n$ (\%).

Abbreviations: 5-ASA, 5- aminosalicylic acid; CD, Crohn's disease; UC, ulcerative colitis; IFX, Infliximab; MTX, methotrexate; Vedo, vedolizumab; Cico sp, Ciprofloxacin.

of female gender, patients of high cutural level, high sócioeconomic status, high level of education, urban residency, and being employed in our data, and even though we have not found any statistical significance for these factors, this study reinforces similarities of epidemiological studies previ-
Table 6 Extra-intestinal manifestation of inflammatory bowel disease patients

\begin{tabular}{|l|l|l|l|}
\hline Manifestation & $\mathbf{n}$ & $\%$ & $\mathbf{9 5 \%} \mathbf{~ C l}$ \\
\hline Dry eye & 58 & 17.6 & $(13.5 ; 21.4)$ \\
\hline Kidney stones & 57 & 17.3 & $(I 3.2 ; 2 I .4)$ \\
\hline Osteopenia & 50 & 15.2 & $(I I .3 ; 19.1)$ \\
\hline Osteoporosis & 28 & 8.5 & $(5.5 ; 1 I .5)$ \\
\hline Erythema nodosum & 18 & 5.5 & $(3.0 ; 7.9)$ \\
\hline Oral ulcers & 8 & 2.4 & $(0.8 ; 4.1)$ \\
\hline Uveitis & 8 & 2.4 & $(0.8 ; 4.1)$ \\
\hline
\end{tabular}

ously published in developed countries. ${ }^{44-46}$ We also noticed that European descendants were the most affected by these diseases. This reflects the local population. Differently from Sousa et al's study, inflammatory diseases have been shown to be incapacitating where the patients were unable to study or work, with high rates of Brazilian government assistance. ${ }^{16}$ These conflicting results could reflect the difficulties these patients face in reaching a public referral center in this region.

For $\mathrm{CD}$, the Montreal classification patterns showed the predominance of inflammatory behavior in B1 (68.9\%), B2 (17\%), B3 (7.6\%) p 6.6\%, and side in L3 (42.2\%), L1 (37.4\%), and L2 (19.9\%) (Table 2), with a side pattern compatible with that described in the literature. In the sample, inflammation 
was the most common, similar to that found by Parente et al. ${ }^{28,47,48}$ We can suggest that in our data, Chron's disease is more frequent. This is probably due to the fat that we are a referral center and our patients presented more severe diseases.

Regarding UC (Montreal classification), we noted that S1 and S2 were more frequent in this sample as well as E1 and E2 (Table 2). This pattern was also similar to those found in the northeast and southeast, consistent with the global literature. ${ }^{28,47}$ Furthermore, we noticed an increasing number of new cases of the disease over time, with a peak in $2007(P=0.046)$ (Figure 1).

Interestingly, Farrukh et al, during the period from 1996-2005, revealed that although the number of UC cases in Brazil increased over time, the rate of new-onset cases of CD increased steadily and was 18 times higher in 2005 than at the beginning of the study. ${ }^{29}$ Intriguingly, a Hispanic survey ended 1 year after the data collection at the private center in question began and could be a "mirror image" of what was happening in the country (namely, an increase in the incidence of $\mathrm{CD}$, with a consequent reduction in UC). ${ }^{29}$

Regarding the relationship between environmental factors and the diseases, current smoking, anti-inflammatories, oral contraceptives, prior tonsillectomy and appendectomy were evaluated during this time but they were not found to be statistically significant in this study. ${ }^{49-52}$ This implies that there is a need for future studies that may connect the time of exposure to these factors in relation to the protection of the diseases or risk involved.

In this study, diarrhea was the predominant symptom, along with the presence of blood in the feces. When separately analyzing the diseases correlated with $\mathrm{UC}$, bleeding and diarrhea were the most common (70\%); however, in CD, there were a predominance of diarrhea $(25.5 \%)$ and weight loss $(25.5 \%)$, followed by others, as shown in Table 4 .

Our results were similar to the results of Delmondes et al, which described similar symptoms when analyzing patients with UC, finding a predominance of diarrhea with bleeding in $71 \%$ of the cases and only diarrhea for patients with CD (59\%). ${ }^{44,47}$

Our findings demonstrate that the time between clinical symptomatology and a definitive diagnostic investigation was 58-62 months $(P<0.77)$ (Figure 2). Previous studies referred to a period of 5-10 years for this interval..$^{53,54}$ In our study, over time, Humira was used more frequently than Infliximab. This factor is probably due to the fact that we are a referral center treating patients whose previous treatments had failed, including infliximab.

Among the extra-intestinal manifestations, dry eye and kidney stones were the most frequent (Table 6). Two previously published large, prospective studies with this same group of patients demonstrated the direct relationship between renal and dry eye and the use of mesalazine. ${ }^{55,56}$

Despite the fact that some patients underwent surgery, we have not observed neoplasia up until now.

\section{Conclusion}

This is an unpublished study developed in Brazil in a private health care center, since there have only been studies in this country in public centers and a large number of patients with inflammatory disease has been shown, with increasing numbers of these cases since 2007. Regarding clinical symptoms, diarrhea/bleeding followed by weight loss represented the major important signs that led to diagnosis, suggesting that more attention should be paid to an investigation which is quicker, aiming for an early diagnosis in order to avoid future complications of the inflammatory disease. The time to diagnosis was longer for patients with UC than for those with CD; the delay in diagnosis in Brazil is still a concern for these patients. Regarding drug approaches, biologic therapy represented $>50 \%$ of the drugs, showing that we had patients with severe disease in this series, in some cases reinforcing the indication for cellular transplantation, though in isolated situations. Therefore, IBD is not just a public health care reality, this study confirms the importance of being alert to the signs, and of recommending treatment sooner.

\section{Acknowledgments}

We would like to acknowledge Dr Alan Colm Moss, Dr Geraldo Elias, and Dr Decio Iandoli Junior.

\section{Disclosure}

DB Cury: speaker (Abbvie, Ferring, Jansen and UCB Biopharma); scientific Materials: Jansen, Ferring and Abbvie; visiting Professor at Brigham Women's Hospital. MS Cury: director of the Advanced Endoscopy Center at Scope Clinic.

The authors report no other conflicts of interest in this work.

\section{References}

1. Vinter-Repalust N. [Chronic inflammatory bowel diseases - specific aspects of family physician care]. Acta Med Croatica. 2015;69(4):395-399.

2. Carlsson E, Persson E. Living with intestinal failure caused by Crohn disease: not letting the disease conquer life. Gastroenterol Nurs. 2015;38(1):12-20. 
3. Kemp K, Griffiths J, Lovell K. Understanding the health and social care needs of people living with IBD: a meta-synthesis of the evidence. World J Gastroenterol. 2012;18(43):6240.

4. Loftus EV. Crohn's disease: etiology, complications, assessment, therapy, and management. Gastroenterology Clinics of North America. 2017;46(3):xiii-0.

5. Zhou M, He J, Shen Y, Zhang C, Wang J, Chen Y. New frontiers in genetics, gut microbiota, and immunity: a Rosetta stone for the pathogenesis of inflammatory bowel disease. BioMed Research International. 2017;2017(9):1-17.

6. Maaser C, Langholz E, Gordon H, et al. DOP001 European Crohn's and colitis organisation topical review on environmental factors in IBD. $J$ Crohns Colitis. 2017;11(suppl_1):S26-920.

7. Cury DB, Mizsputen SJ, Versolato C, et al. Serum calprotectin levels correlate with biochemical and histological markers of disease activity in TNBS colitis. Cell Immunol. 2013;282(1):66-70.

8. Ortizo R, Lee SY, Nguyen ET, Jamal MM, Bechtold MM, Nguyen DL. Exposure to oral contraceptives increases the risk for development of inflammatory bowel disease: a meta-analysis of case-controlled and cohort studies. Eur J Gastroenterol Hepatol. 2017;29(9):1064-1070.

9. Cury DHB, Costa JE, Irika K, et al. Protective effect of octreotide and infliximab in an experimental model of indomethacin-induced inflammatory bowel disease. Dig Dis Sci. 2008;53(9):2516-2520.

10. Burke KE, Boumitri C, Ananthakrishnan AN. Modifiable environmental factors in inflammatory bowel disease. Curr Gastroenterol Rep. 2017;19(5):21.

11. Bianco AM, Girardelli M, Tommasini A. Genetics of inflammatory bowel disease from multifactorial to monogenic forms. World J Gastroenterol. 2015;21(43):12296-12310.

12. Flanagan P, Campbell BJ, Rhodes JM. Bacteria in the pathogenesis of inflammatory bowel disease. Biochem Soc Trans. 2011;39(4):1067-1072.

13. Li SX, Thompson KD, Peterson T, et al. Delivering high value inflammatory bowel disease care through telemedicine visits. Inflamm Bowel Dis. 2017;23(10):1678-1681.

14. Burisch J, Vardi H, Pedersen N, et al. Costs and resource utilization for diagnosis and treatment during the initial year in a European Inflammatory bowel disease inception cohort: an ECCO-EpiCom study. Inflamm Bowel Dis. 2015;21(1):121-131.

15. Peyrin-Biroulet L. What is the patient's perspective: how important are patient-reported outcomes, quality of life and disability? Dig Dis. 2010;28(3):463-471.

16. de SBFR. Carvalho ATP, de VCA, et al. "The socio-economic impact of work disability due to inflammatory bowel disease in Brazil'. Eur J Health Economics. 2017.

17. Bernstein CN, Eliakim A, Fedail S, et al. World gastroenterology organisation global guidelines inflammatory bowel disease: update August 2015. J Clin Gastroenterol. 2016;50(10):803-818.

18. Lopez RN, Evans HM, Appleton L, et al. Point prevalence of pediatric inflammatory bowel disease in New Zealand in 2015: initial results from the PINZ study. Inflamm Bowel Dis. 2017;23(8):1418-1424.

19. Däbritz J, Gerner P, Enninger A, Claßen M, Radke M. Inflammatory bowel disease in childhood and adolescence. Dtsch Arztebl Int. 2017;114(19):331-338.

20. Kaplan GG, Ng SC. Globalisation of inflammatory bowel disease: perspectives from the evolution of inflammatory bowel disease in the UK and China. Lancet Gastroenterol Hepatol. 2016;1(4):307-316.

21. Lophaven SN, Lynge E, Burisch J. The incidence of inflammatory bowel disease in Denmark 1980-2013: a nationwide cohort study. Aliment Pharmacol Ther. 2017;45(7):961-972.

22. Burisch J, Munkholm P. The epidemiology of inflammatory bowel disease. Scand J Gastroenterol. 2015;50(8):942-951.

23. Guariso G, Gasparetto M. Treating children with inflammatory bowel disease: current and new perspectives. World J Gastroenterol. 2017;23(30):5469-5485.

24. Akere A, Oke TO, Otegbayo JA. Colonoscopy at a tertiary healthcare facility in Southwest Nigeria: spectrum of indications and colonic abnormalities. Ann Afr Med. 2016;15(3):109-113.
25. den Y, Kinoshita J, Deshpande GA, Hiraoka E. Amoebiasis masquerading as inflammatory bowel disease. BMJ Case Rep. 2015;2015.

26. Santos RMD, Carvalho ATP, Silva KDS, Sá SPC, Santos AHD, Sandinha MR. Inflammatory bowel disease: Outpatient treatment profile. Arq Gastroenterol. 2017;54(2):96-100.

27. da Silva BC, Lyra AC, Mendes CMC, et al. The demographic and clinical characteristics of ulcerative colitis in a northeast Brazilian population. BioMed Research International. 2015;2015(1):1-8.

28. Parente JML, Coy CSR, Campelo V, et al. Inflammatory bowel disease in an underdeveloped region of northeastern Brazil. World J Gastroenterol. 2015;21(4):1197-1206.

29. Farrukh A, Mayberry JF. Inflammatory bowel disease in Hispanic Communities: a concerted South American approach could identify the aetiology of Crohn's disease and ulcerative colitis. Arq Gastroenterol. 2014;51(4):271-275

30. da Silva BC, Lyra AC, Rocha R, Santana GO. Epidemiology, demographic characteristics and prognostic predictors of ulcerative colitis. World J Gastroenterol. 2014;20(28):9458-9467.

31. Oliveira FM, Emerick APC, Soares EG. [Epidemiology aspects of inflammatory bowel disease in the east region of Minas Gerais State]. Cien Saude Colet. 2010;15 Suppl 1(Suppl 1):1031-1037.

32. Brazilian Study Group of Inflammatory Bowel Diseases. "Consensus guidelines for the management of inflammatory bowel disease.". Arquivos de Gastroenterologia. 2010;47(no. 3):313-325.

33. Biancone L, Annese V, Ardizzone S, et al. Safety of treatments for inflammatory bowel disease: clinical practice guidelines of the Italian Group for the study of inflammatory bowel disease (IG-IBD). Dig Liver Dis. 2017;49(4):338-358.

34. Spekhorst LM, Visschedijk MC, Alberts R, et al. Performance of the Montreal classification for inflammatory bowel diseases. World J Gastroenterol. 2014;20(41):15374-15381.

35. Loftus EV. Clinical epidemiology of inflammatory bowel disease: incidence, prevalence, and environmental influences. Gastroenterology. 2004;126(6):1504-1517.

36. Fernandes A, Bacalhau S, Cabral J. "[Pediatric inflammatory bowel disease: is it still increasing?]." Acta Medica Portuguesa. 2011;24(Suppl 2). Portuguese.

37. Bhan N, Millett C, Subramanian SV, et al. Socioeconomic patterning of chronic conditions and behavioral risk factors in rural South Asia: a multi-site cross-sectional study. Int J Public Health. 2017;62(9):1019-1028.

38. Abegunde AT, Muhammad BH, Bhatti O, Ali T. Environmental risk factors for inflammatory bowel diseases: evidence based literature review. World J Gastroenterol. 2016;22(27):6296-6317.

39. Ng SC. Epidemiology of inflammatory bowel disease: focus on Asia. Best Pract Res Clin Gastroenterol. 2014;28(3):363-372.

40. Zakharia K, Tabibian A, Lindor KD, Tabibian JH. Complications, symptoms, quality of life and pregnancy in cholestatic liver disease. Liver Int. 2018;38(3):399-411.

41. Bye WA, Nguyen TM, Parker CE, Jairath V, East JE, Cochrane IBD Group. Strategies for detecting colon cancer in patients with inflammatory bowel disease. Cochrane Database of Systematic Reviews. 2017;13(2):CD000279.

42. Chrobak-Bień J, Gawor A, Paplaczyk M, Małecka-Panas E, Gąsiorowska A. Analysis of factors affecting the quality of life of those suffering from Crohn's disease. Pol Przegl Chir. 2017;89(4):16-22.

43. Cantoro L, di Sabatino A, Papi C, et al. The time course of diagnostic delay in inflammatory bowel disease over the last sixty years: an Italian multicentre study. J Crohns Colitis. 2017;11(8):975-980.

44. Kedia S, Ahuja V. Epidemiology of inflammatory bowel disease in India: the great shift East. Inflamm Intest Dis. 2017;2(2):102-115.

45. Ng WK, Wong SH, Ng SC. Changing epidemiological trends of inflammatory bowel disease in Asia. Intest Res [Internet]. 2016 Apr [January 10, 2019];14(2):111-9.

46. Yang S-K. How does the epidemiology of inflammatory bowel disease differ between East and West? a Korean perspective. Inflamm Intest Dis. 2017;2(2):95-101. 
47. Delmondes LM, Nunes MO, Azevedo AR, Oliveira Mmdes, Coelho LER, Torres-Neto Jdar. Clinical and sociodemographic aspects of inflammatory bowel disease patients. Gastroenterology Res. 2015;8(3-4):207-215.

48. Victoria CR, Sassak LY, Nunes Hrdec. Incidence and prevalence rates of inflammatory bowel diseases, in midwestern of São Paulo State, Brazil. Arq Gastroenterol. 2009;46(1):20-25.

49. Gaburri PD, Chebli JM, de Castro LE, et al. [Epidemiology, clinical features and clinical course of Crohn's disease: a study of 60 cases]. Arq Gastroenterol. 1998;35(4):240-246. Portuguese

50. Berg AM, Dam AN, Farraye FA. Environmental influences on the onset and clinical course of Crohn's disease-part 2: infections and medication use. Gastroenterol Hepatol. 2013;9(12):803-810.

51. van der Sloot KWJ, Amini M, Peters V, Dijkstra G, Alizadeh BZ. Inflammatory bowel diseases: review of known environmental protective and risk factors involved. Inflamm Bowel Dis. 2017;23(9): 1499-1509.
52. Sun W, Han X, Wu S, Yang C. Tonsillectomy and the risk of inflammatory bowel disease: a systematic review and meta-analysis. J Gastroenterol Hepatol. 2016;31(6):1085-1094.

53. Solberg IC, Lygren I, Jahnsen J, et al. Clinical course during the first 10 years of ulcerative colitis: results from a population-based inception cohort (IBSEN study). Scand J Gastroenterol. 2009;44(4): $431-440$.

54. Nguyen VQ, Jiang D, Hoffman SN, et al. Impact of diagnostic delay and associated factors on clinical outcomes in a U.S. Inflammatory bowel disease cohort. Inflamm Bowel Dis. 2017;23(10):1825-1831.

55. Cury DB, Moss AC, Schor N. Nephrolithiasis in patients with inflammatory bowel disease in the community. Int J Nephrol Renovasc Dis. 2013;6:139.

56. Cury DB, Moss AC. Ocular manifestations in a community-based cohort of patients with inflammatory bowel disease. Inflamm Bowel Dis. 2010;16(8):1393-1396.
Journal of Inflammation Research

\section{Publish your work in this journal}

The Journal of Inflammation Research is an international, peer-reviewed open access journal that welcomes laboratory and clinical findings on the molecular basis, cell biology and pharmacology of inflammation including original research, reviews, symposium reports, hypothesis formation and commentaries on: acute/chronic inflammation; mediators of

\section{Dovepress}

inflammation; cellular processes; molecular mechanisms; pharmacology and novel anti-inflammatory drugs; clinical conditions involving inflammation. The manuscript management system is completely online and includes a very quick and fair peer-review system. Visit http://www.dove press.com/testimonials.php to read real quotes from published authors.

Submit your manuscript here: https://www.dovepress.com/journal-of-inflammation-research-journal 